\title{
Technology, Recommendation and Design: On Being a 'Paternalistic' Philosopher
}

\author{
Pak-Hang Wong
}

Received: 17 April 2011/Accepted: 16 June 2011/Published online: 29 June 2011

(C) The Author(s) 2011. This article is published with open access at Springerlink.com

\begin{abstract}
Philosophers have talked to each other about moral issues concerning technology, but few of them have talked about issues of technology and the good life, and even fewer have talked about technology and the good life with the public in the form of recommendation. In effect, recommendations for various technologies are often left to technologists and gurus. Given the potential benefits of informing the public on their impacts on the good life, however, this is a curious state of affairs. In the present paper, I will examine why philosophers are seemingly reluctant to offer recommendations to the public. While there are many reasons for philosophers to refrain from offering recommendations, I shall focus on a specific normative reason. More specifically, it appears that, according to a particular definition, offering recommendations can be viewed as paternalistic, and therefore is prima facie wrong to do so. I will provide an argument to show that the worry about paternalism is unfounded, because a form of paternalism engendered by technology is inevitable. Given the inevitability of paternalism, I note that philosophers should accept the duty to offer recommendations to the public. I will then briefly turn to design ethics, which has reconceptualised the role of philosophers and, in my mind, fitted well with the inevitability of paternalism. Finally, I shall argue that design ethics has to be supplemented by the practice of recommendation if it is to sustain its objective.
\end{abstract}

Keywords Paternalism - Recommendation - Design ethics - Good life · Role of philosopher

P.-H. Wong (ه)

Department of Philosophy, Faculty of Behavioral Sciences, University of Twente,

Postbox 217, 7500 AE Enschede, The Netherlands

e-mail: p.h.wong@utwente.nl

URL: http://www.wongpakhang.com 


\section{Introduction}

In reflecting on the current state and future prospects of philosophy and ethics of technology, Brey (2010a) and Verbeek (2010) have noted that the field in its current state, especially in the discussions of normative issues surrounding technology, has focused too narrowly on moral values, i.e. the right and the just. The main question in the field can thus be summarised as: Is this or that technology morally (or politically) dubious? And, if so, what should we do about it? As such, philosophers have spent most of their energy to establish boundaries between technology and humanity and to prevent intrusions of technologies into certain areas of people's life. Accordingly, philosophers and ethicists conceived of themselves as protectors of humanity from threats of technology. For Brey and Verbeek, this narrow focus is unpromising, and they argue that researchers should broaden their scope of inquiry to cover the issues related to people's good life because of the possible impacts of technology on people's ways of living. Philosophers should, in other words, pay more effort to study potential contributions of technology to the good life. I think Brey and Verbeek have rightly directed our attention to an important but neglected aspect. I agree with them that philosophers should pay more effort to improve human-technology relationships than to condemn technologies outright, but the question is: how should philosophers do that?

For Verbeek, the answer to this question lies in "an ethics of 'accompany technology' [that aims] to accompany the development, use and social embedding of technology." (Verbeek 2010, 52) This, Verbeek argues, requires philosophers (i) to participate and intervene in the design and production of technology and (ii) to enable users and policy-makers to better understand technologies and their potential impacts on their good life. While Verbeek and others have devoted a considerable number of works to the first half of this project through the ethics of and in design, relatively little effort has been directed at the second half of the project. ${ }^{1}$ This paper will continue the discussion they have initiated, and my emphasis will be placed on the second part of Verbeek's project. Here, I will reflect on the role of philosophers with respect to technology and the public, argue for a specific role for philosophers and illustrate how this role can be best fulfilled.

Philosophers have talked to each other about moral issues concerning technology, but few of them have talked about issues of technology and the good life, and even fewer have talked about technology and the good life with the public in the form of recommendation. In effect, recommendations for various technologies are often left to technologists and gurus. Notably, a surging number of popular 'technology writings' recommending how people should live with new and emerging technology are offered by them, e.g. Keen (2007), Carr (2010), Lanier (2010), Shirky (2010) and Powers (2010). Many of them are, of course, capable experts of technology. Yet, it is less clear that they are equally experts of the good life. Given the potential benefits of informing the public on technology's impacts on

\footnotetext{
1 Interesting, Verbeek has himself mentioned that "the ethics of accompaniment also engages with the ways in which users help to incorporate technologies in their life, and policy-makers help to shape the role of technologies in social practices." However, Verbeek has yet to pursue this part of "accompanying technology" in his own works.
} 
the good life, the absence of philosophers is a curious state of affairs. And, I think, their absence in offering recommendations to the public far is from optimal. In the next section, I will examine why philosophers are seemingly reluctant to offer recommendations to the public. While there are many reasons, including sociological, conceptual and normative reasons, for philosophers to refrain from offering recommendations, I shall focus on a specific normative reason. More specifically, it appears that, according to a particular definition, offering recommendations can be viewed as paternalistic, and therefore is prima facie wrong to do so. I will provide an argument to show that the worry of paternalism is unfounded, because a form of paternalism engendered by technology is inevitable. Given the inevitability of paternalism, I note that philosophers should accept the duty of offering recommendations to the public. I will then briefly turn to design ethics, which has reconceptualised the role of philosophers and, in my mind, fitted well with the inevitability of paternalism. My brief discussion of design ethics, however, is not intended to offer any arguments for or against design ethics. Instead, my aim is to point out that design ethics, although being one of the best responses to the inevitability of paternalism, still has to be supplemented by the practice of recommendation if it is to attain its objective at all. Finally, I will argue that a Walzerian approach to recommendation can provide a helpful starting point to philosophers to engage in the practice of recommendation.

\section{Perils of Recommendation?}

A number of reasons are proposed to account for why philosophers-and, academics in general-have refrained themselves from offering recommendations to the public. For example, Russell Jacoby (2000) has developed an interesting sociological account of the decline of public intellectuals. ${ }^{2}$ Fuller (2004) has argued that there is a demise of the conceptual conditions necessary for the existence of public intellectuals in the 21st century. Likewise, Alcoff (2002) has discussed the doubts on academic integrity of the works directed at the public. Instead of pursuing them further, I want to focus on one aspect which, I think, has led philosophers to excuse themselves from the practice of recommendation, namely offering recommendations to the public can be viewed as paternalistic. It should be noted that not all recommendations to the public are paternalistic in a way that troubles philosophers and that whether recommendations are paternalistic is not independent from one's definition of paternalism. Hence, I will first identify the relevant type of recommendation in question. I will then examine some characteristics of paternalism. Instead of arguing for a particular definition of paternalism, however, I will look at what make paternalism objectionable and so being prima facie undesirable to philosophers. I will argue that the type of recommendation in question can raise paternalistic worry because, like other paternalistic behaviours or practices, it seems to interfere with people's liberty and autonomy by imposing a

\footnotetext{
2 This study only has examined public intellectuals in the American context, but he has later attempted to revise and extend his thesis to other regions, see Jacoby (2009).
} 
view of the good life on them, and it also seems to insult by telling them how that they should live their own life and thereby debasing them.

Broadly speaking, a person $P$ offers someone $Q$ a recommendation when (i) $P$ explicitly tells $Q$ that $Q$ ought to do $X$ because (ii) ( $P$ thinks that) doing $X$ is good/good for $S .^{3}$ For my current purpose, (ii) should be interpreted as: ( $P$ thinks that) doing $X$ is prudentially good for $Q$. Given this definition, two types of recommendation can be further subdivided, i.e. binding and non-binding recommendation. Binding recommendation is normative in that $P$ assumes a position, in which $P$ is to fault $Q$ if $Q$ fails to do what is being recommended to him or her, whereas non-binding recommendation does not carry similar normative force. ${ }^{4}$ In other words, non-binding recommendation can be viewed as a form of suggestion, where a person's non-compliance shall not invite criticisms. It is the combination of binding recommendation and the placement of the person $Q$ as $S$ in (ii) that, I think, renders the practice of recommendation seemingly paternalistic.

Let's now turn to paternalism. There are various definitions of paternalism and/or criteria for a behaviour or practice to be counted as paternalistic. ${ }^{5}$ So, whether offering recommendations is paternalistic or not effectively depends on one's definition and/or criteria. It is not my aim to provide an exact definition of paternalism. Rather, I want to explain why paternalistic behaviours and practices are deemed objectionable by looking at those definitions and criteria. Kalle Grill (2011) has helpfully suggested four parameters for defining paternalism, namely the interference condition, the consent condition, the benevolence condition and the superiority condition. ${ }^{6}$ One way or another, these conditions make paternalism problematic. In the following, I shall look at these conditions and explain why they create a sense of uneasiness. At the same time, I shall illustrate how the relevant type of recommendation, i.e. binding recommendation, fits those conditions, and so being paternalistic and prima facie undesirable.

\footnotetext{
${ }^{3}$ Here, recommendation is formulated positively, i.e. it is to encourage a person to do something. It can also be formulated negatively to discourage a person from doing something too. But, I will only discuss positive recommendation in this paper. Also, since the present study aims at the relation between technology and the good life, I will set aside the distinction between goodness-for and good simpliciter. As it should be clear later, the practice of recommendation becomes especially problematic when $S$ refers to the person $Q$.

${ }^{4}$ An anonymous reviewer rightly pointed out that there are, at least, two forms of binding recommendation. There are strong binding recommendation that involves legal and/or economic sanctions upon non-compliance, and weak binding recommendation that does not necessarily involve legal and economic sanctions. I assume the normativity of weak binding recommendation is primarily moral and prudential; in other words, a person's failure to comply with weak binding recommendation should invite moral and/or prudential criticisms of the person but not necessarily more than that. While the discussion of strong binding recommendation is an interesting topic for philosophical and policy debate and is rightly under the scope of paternalism, this paper is about weak binding recommendation. Since offering weak binding recommendations is what is currently being done almost exclusively by technologists and gurus, and the aim of the present paper is to urge philosophers to take up this task. Although weak binding recommendation may not be under the scope of paternalism in the strict sense, the status of weak binding recommendation, i.e. whether it raises paternalistic worry or not, is directly related to the willingness of philosophers to offer recommendations to the public.

${ }^{5}$ See, e.g. Garren (2006, 2007), Dworkin (2010) and Grill (2011)

${ }^{6}$ Cf. Dworkin (2010)
} 
The interference condition states that paternalism involves interfering with a person's course of action against the person's will in spheres of life that are under the person's legitimate control. In other words, paternalism involves interference of a person's "liberty and autonomy". (Dworkin 2010) Interference is typically interpreted as a closing of the person's choices that are otherwise available, or as a substitution of the person's judgement and agency by inducing certain decisions and/or actions. Note that, however, interference is not necessarily coercive, it can be achieved through deception, manipulation and incentivisation. (Scoccia 2008; Thaler and Sunstein 2008) The interference condition (and, by extension, paternalism) is seemingly objectionable because it clashes with our intuition that human being should be free and autonomous, at least, for matters that lie squarely in spheres that are under a person's control. According to this intuition, people should be left alone for their rational decisions and actions. Otherwise, one is imposing a view of what is good and bad on that person, which the person does not necessarily agree. In this respect, binding recommendation satisfies the interference condition because it does limit people's choices by imposing (moral) cost on their noncompliance; or, it replaces their judgement and agency by claiming that they should follow a specific decision and/or action regardless of their own will.

It is debatable whether binding recommendation is genuinely paternalistic. For example, if a binding recommendation is accompanied by reasons to follow it, then it seems to become an attempt of rational persuasion, which few would label as paternalistic. It is so because in giving reasons to follow the (binding) recommendation, the person who gives the recommendation is facilitating better judgements of other people, and so helping them to truly realise their agency. It is, indeed, true that binding recommendations can be given in the form of rational persuasion. But, the question is that is rational persuasion sufficient to satisfy the requirements for the expression of the duty of a philosopher. In other words, should philosophers stop at giving reasons for doing something? I think there is a significant difference between binding recommendation and rational persuasion, and rational persuasion is not always the best way to convince the public, especially on issues about technology and the good life. Although I contend that rational persuasion may be a better way to convince the public to adopt technology in a specific way, rational persuasion appears to be insufficient to settle the issues because of pluralism of value. Imagine, for example, a philosopher trying to convince the digital natives the potential vices of Social Networking Sites, arguing that they will have adverse effects on their privacy, the nature of friendship or their good life in general, and they do so by giving prudential reasons to support their claims. Still, the digital natives can easily reject the philosopher's claim-not necessarily because of the philosopher has made disputable factual claims - because they hold a different view of the good life, which warrants their way of using Social Networking Sites. In this scenario, holding on to rational persuasion requires the philosopher to leave the disagreement as it is as long as the digital natives can offer rational replies based on their view of the good life. In other words, philosophers appear to be inept to alter the behaviour and practice, which they see (un)desirable, if two or more fundamentally different views of the good life are in question. If philosophers want to be effective in encouraging and discouraging certain behaviours and 
practices, they have to be prepared for promoting or demoting a specific view of the good life, and even when rational persuasion fails, they should be prepared to praise (or condemn) what they see (un)desirable with respect to the view they hold of the good life.

The weakness of rational persuasion with respect to technology and the good life, in comparison to binding recommendation, is that it requires an agreeable common ground if rational persuasion is to be successful at all. However, it is not entirely clear that such an agreeable common ground can be established for the issues on the good life. It will be an ideal scenario if philosophers can convince the public simply by rational persuasion, but in reality there are different views of the good life that make it impossible. If philosophers hold on only to rational persuasion, they are bound to be silent when disagreements arise.

Of course, not all kinds of interference are objectionable. Particularly, it has been argued that if the person consents to the interference, then it is justifiable. The consent condition is about whether the person being intervened with consent to the interference or not. In a situation where the interference is not consented, it is known as a form of "hard" paternalism, whereas in a situation where the interference is consented, it is often labelled as "soft" paternalism. And, "soft" paternalism is typically seen as unproblematic. ${ }^{7}$ Now, whether binding recommendation belongs to "hard" or "soft" paternalism is to be determined by people's consents to philosophers who offer binding recommendations to them. Although it is theoretically possible to obtain consent from people being recommended, it seems practically impossible to obtain consent prior to binding recommendation being offered to them. ${ }^{8}$

The benevolence condition states that paternalism is directed at a person's own good. In other words, it is the placement of the person as $S$ in (ii) in my definition of recommendation. The benevolence condition in itself is not objectionable, but it implicitly presupposes that a person $P$, i.e. the person being paternalistic, is in a better position than another person $Q$ to determine what is good and bad for $Q$, thereby $P$ is in a superior position than $Q$ with respect to matters that belong to $Q$ 's legitimate control. Hence, paternalism exhibits a form of elitism, that is-it satisfies the superiority condition. And, this is objectionable because it is considered to be an insult to an otherwise competent person, who is viewed incapable of living his or her own life. Clearly, in offering a binding recommendation, a person $P$ is committed to the superiority condition in that $P$ is claiming that $Q$, who has been offered the recommendation, ought to follow what $P$ says; and, $Q$ 's failure to do so will elicit criticisms from $P$.

There is, however, one caveat to the superiority condition. Consider in what situation $P$ is in a rightful position to instruct $Q$ 's decision and action? Intuitively, when $P$ is an expert on the matters related to $Q$ 's decision and action, then $P$ is in a

\footnotetext{
7 See, Feinberg (1986). Joel Feinberg's discussion of 'hard' and 'soft' paternalism, I think, is most influential in the field.

${ }^{8}$ Philosophers, of course, can offer binding recommendations on the assumption that there is hypothetical consent between them and the public, or to have subsequent consent from the public afterwards. As Van De Veer (1979) has pointed out, however, neither hypothetical consent nor subsequent consent is the same as actual consent.
} 
rightful position to offer $Q$ instructions. In other words, when $P$ is an expert on the relevant issues, then $P$ can rightly be in a superior position. Yet, whether there can be expertise on the issues pertaining to the good life is much disputed. It is often held that questions about the good life, i.e. how people should live their, are personal and subjective, and therefore no expertise-except for the person in question-is warranted. ${ }^{9}$ Hence, philosophers who offer (binding) recommendations to the public may risk being seen as groundless, i.e. there are no grounds for philosophers to recommend their own view(s) of the good life to the public in $a$ binding manner, idiosyncratic, i.e. it is only philosophers' own the view(s) of the good life but not necessarily applicable to the others, and elitist. In short, the questionability of expertise on the good life has contributed to philosophers' hesitation to the practice of recommendation because of the superiority condition.

\section{Paternalism is Inevitable: An Inconvenient Truth}

If offering recommendations to the public can be viewed as paternalistic, and paternalism is objectionable, then philosophers are right to refrain themselves from doing so. However, if paternalism is inevitable, then perhaps philosophers should not be preoccupied with the question of why paternalism is objectionable or when it is justifiable, but to reconsider their role in light of its inevitability. In this section, I want to offer an argument against the possibility of non-paternalistic condition, thereby to urge philosophers to reconsider the prospects of the practice of recommendation. The argument, however, should not be misunderstood as an endorsement of paternalism. Nor should it be understood as an argument in favour of paternalism. This argument aims to show that paternalism is inevitable, and it is currently practised by designers and engineers (at the stage of design and production) and technologists and gurus (at the stage of everyday usage), which neither of them is an ideal candidate for the task. Philosophers' involvement, I think, can provide a better alternative to the current situation. My argument can be formulated as follows:

(P1) Non-paternalistic condition. People should be left alone in the spheres of life that is under their legitimate control (provided that no harm is inflicted on others). This means that people should be able to live their life in accordance to their view of the good life, and no view of the good life should be imposed on them.

(P2) Plurality of the good life. In the contemporary society, there are diverse, and possibly conflicting, views of the good life that are equally valid.

(P3) Technology is not neutral. There are values embedded in technology, and users of technology are necessarily influenced, constrained and/or shaped by them.

\footnotetext{
9 See, e.g. (Cowley 2005) and Steinkamp et al. (2008, 175-177). Note that the debate on moral expertise is typically centred on morality in the narrow sense, i.e. the right. I think the problem for expertise on the good life is even more acute than expertise on morality in the narrow sense, because it is more difficult to provide a (normative) standard to the expertise in question.
} 
(P4) Technological design and production elitism. Technology is designed and produced by a small number of specialists, e.g. designers, engineers, etc. Ordinary people, i.e. the public, cannot (always) be directly involved in technological design and production.

(P5) Mismatches of the good life. Given (P2), (P3) and (P4), there are bound to be mismatches between the views of the good life held by the users of technologyor, the public - and the values proffered by the technology, which are selected and implemented by elitists in technological design and production.

(C) Inevitability of paternalistic condition. Given (P5), (P1) is unattainable.

(P1) describes the condition in which people are free from interference on the matters that are under their legitimate control. And, this kind of interference is objectionable because it imposes a view of the good life-or, more accurately, a view on how people should live-on the people. By showing that such a condition is unattainable, I hope it can mitigate the uneasiness associated with paternalistic behaviours and practices.

(P2) is generally accepted by liberal theorists. ${ }^{10}$ And, it is often cited in support of the importance of (P1), that is-if there are different views of the good life that are equally valid, then it appears that there is no good justification to impose a specific view of the good life on another person. Conversely, if there is only one valid view of the good life, then it seems that there is, at least, one ground to impose that view of the good life on the people, namely it is the true view of the good life.

(P3) summarised one of the major lesson we learnt from science and technology studies, namely technology is value-laden. (e.g. Winner 1986; Brey 2010b) In a nutshell, it amounts to the claim that values are built into technology at the stage of its design and production by opening up certain options or making them more accessible to the users, and vice versa. And, users of technology are influenced, constrained or shaped by the values proffered by the technology in question. In effect, I think (P3) in itself is sufficient to demonstrate the unattainability of (P1): if values are built into technology, and users of technology are influenced, constrained and shaped by them. As long as the users are using the technology, they cannot escape from the values proffered by the technology being imposed on them. In other words, users will not be left alone by the technology in the spheres that are under their legitimate control. Still, I want to introduce an additional premise to illustrate the nature of the values being built into the technology with (P4).

I intended (P4), I hope uncontroversially, to be a statement of fact. In most technological design and production processes, users are conceived as passive receivers of technology, who are not and often cannot be involved in the processes. ${ }^{11}$ The passivity of users has an important implication to the present

\footnotetext{
${ }^{10}$ See, e.g. Rawls (1993). Rawls called this "the fact of reasonable pluralism", i.e. "a pluralism of comprehensive religious, philosophical, and moral doctrines [and, more importantly,] a pluralism of incompatible yet reasonable comprehensive doctrines." (Rawls 1993, xvi)

11 There are other models of technological design and production in which users (are required to) actively take part in the processes, most notably the (theory of) Participatory Design. See, e.g. Muller and Kuhn (1993), Muller (2007) and Iversen et al. (2010). However, I believe (P4) has captured the common model(s) of technological design and production processes. And, I will return to the other models of design and production in the subsequent discussion.
} 
discussion, as stated in (P3), values are built into technology; and, the values are built into the technology by its designers and engineers, who claim special technical knowledge that are unavailable to the users. Designers and engineers are also the small group of people who oversee the design and production processes. In other words, users are 'instructed' how to live by designers, engineers and the others in the chain of production, who determine-either consciously or unconsciously-the values to be embedded in the technology and, relatedly, decide what is good and bad for the users. ${ }^{12}$ In this respect, designers and engineers cannot but impose a view of the good life on the users.

Finally, (P5) reiterates the fact that people have different views of the good life, which are equally valid, i.e. (P2). Given that technology is not neutral, that isvalues are built into technology either consciously or unconsciously, i.e. (P3), and that it is the designers, engineers and the others in the chain of production, but not the users themselves, who determine the values to be embedded in technology, i.e. (P4). There will be mismatches between the values upheld by the users and those proffered by technology.

So long as people are users of technology, some values (or, views of the good life) are imposed on them. So construed, (P1) is unattainable, i.e. (C).

Two points of clarification should be added before proceeding. Firstly, to reiterate, this argument is not intended to be an argument in favour of paternalism. Or, it may not even be seen as an argument about paternalism in the strict sense. For instance, the values embedded (or omitted) in technology by designers, engineers and other related parties may not aim at the good of the users, but only at their own economic interests. It may well be so. But, it is irrelevant to the argument presented here. The argument here is to show that people cannot be free from values being imposed on them as long as they are users of technology, and thus to urge philosophers to reconsider their duty in light of its inevitability. Secondly, it should be pointed out that my rejection of non-paternalistic condition resides on the assumption that people do not opt out from being the users of technology and that people cannot easily change from one technology to another in order to match it with their own values. Brey (2000) has argued that the values built into technology are often obscure to and hidden from ordinary users of technology. Hence, it will be difficult for them to select and decide at will which technology to use to match their view of the good life. So construed, philosophers and ethicists of technology should, minimally, try to disclose the values embedded in technology and inform the users and policy-makers and enable them to adopt those technologies that suit their view of the good life best. For those who worry about paternalism, however, philosophers should only do so in a descriptive way without normatively affirming any values. But, why stop at descriptively informing the users and policy-makers the values embedded in technology, except because it raises a paternalistic worry? If

\footnotetext{
12 As one anonymous reviewer has pointed out, the view of technology design and production being described here is over-simplified. For instance, other parties, e.g. managers and sale and marketing department, have also played an important part in the design (and production) processes. I contend that the view being described is indeed over-simplistic. However, the argument only requires the claim that ordinary people - the public — do not (and cannot) decide which values to be included (or omitted) in the technology.
} 
paternalism engendered by technology is inevitable, then philosophers should not be afraid of taking up the challenges emerge from the inevitability of paternalism.

\section{Being a 'Paternalistic' Philosopher}

If the argument I presented in the previous section is correct, then paternalism engendered by technology is not something that people can and should avoid. Instead of trying to convince themselves there are ways out of paternalism, philosophers should reconsider their role in light of its inevitability. One direction, as van den Hoven (2008) has noted, is "the Design Turn in Applied Ethics", where philosophers start tinkering with the values embedded in socio-technical systems and technological artefacts during their design and production processes. I think the Design Turn is a fruitful pursuit, but I also think that the turn alone is insufficient to meet the objective it sets for itself. I shall argue that design ethics has to be supplemented by the practice of recommendation if it is to attain its own objective.

\section{Paternalism by Design}

In line with the Design Turn, Verbeek (2006, 2008, 2010) has developed and elaborated Hans Achterhuis's notion of "moralization of technology", which urges ethics of technology to "engage in the development of [technology] that helps to form moral action and decision-making." (Verbeek 2008, 101) Similarly, the theory of Value Sensitive Design (VSD) is intended to be "a theoretically grounded approach to the design of technology that accounts for human values in a principled and comprehensive manner throughout the design process." (Friedman et al. 2008, 69; also see Friedman and Kahn 2007) Either way, in accordance to the Design Turn, philosophers should be actively involved in the design and production processes by helping designers and engineers to select and decide the values to be embedded (and omitted) in technology. In this sense, the Design Turn is essentially paternalistic too. $^{13}$

All is good to philosophers who accept the challenge of the Design Turn. As I have already shown that paternalism engendered by technology is unavoidable, it should not deter philosophers to participate and intervene in the design and production of technology. In short, one of the major objectives of the Design Turn is to improve people's good life through embedding desirable values (or omitting undesirable values) in technology through its design. To meet this objective, however, two important questions have to be answered by philosophers of the Design Turn, i.e.

(1) What values should be embedded (and omitted) in the technology? This question is both methodological and normative. Methodologically, philosophers, together with designers and engineers, need to formulate a method to

\footnotetext{
13 Thaler and Sunstein's notion of nudge is another example of 'paternalism by design'. But, unlike Verbeek's view and the theory of Value Sensitive Design, their account is motivated by inadequacy of human rationality. See, Thaler and Sunstein (2008).
} 
search for the values to be included in (and excluded from) technology. Normatively, they have to determine what values are right, just and/or good to be embedded (and omitted) in the technology.

(2) How to bridge the gap between designer's intention and actual use? Albrechtslund (2007) has argued that theory of VSD and other similar design ethics face a problem he called "the positivist problem". Briefly, the problem arises from the possibility of users departing from designer's intention in actual contexts of use. Hence, designer's intention and actual contexts of use must be somehow be (re)integrated if positive contributions from the Design Turn are to be ensured.

To the first part of (1), researchers of VSD have formulated a "tripartite methodology" that incorporates conceptual, empirical and technical investigations into their analyses. (Friedman et al. 2008, 71-73) Explicit attempts have also been made to apply VSD to ethical issues. (e.g. Cummings 2006) However, it has been argued that the current works in VSD is inadequate for the second part of (1). Particularly, it has been noted that VSD in itself lacks the resource to make normative judgement for design because it is not explicitly aligned with any ethical theories. ${ }^{14}$ And, to (2), Albrechtslund's own proposal is to accept the distinction between the context of design and the actual contexts of use, and to acknowledge the limited role designers and engineers can have on promoting (and demoting) the values. However, the objective of the Design Turn becomes defeasible if users of technology can easily deviate from the intended use. Yet, the distance between designer's intention and the actual contexts of use is inherent to the use of technology. As such, philosophers of the Design Turn cannot limit themselves with design if their objective is to promote the good life through design and technology. They must also be prepared to argue for proper ways of use in terms of the good life the technology aims to promote. However, this kind of arguments will be based on a specific view of the good life, and the users of technology can rationally disagree with philosophers on the claims about the good life. In keeping with the objective of the Design Turn, therefore, philosophers need to find a way to defend the design and the intended use. Since the gap between the intended use and the actual contexts of use cannot be bridged at the stage of design and production, nor it can always be achieved through rational persuasion, binding recommendation offer a valuable option to philosophers to defend the design and close the gap between the intended and actual use of technology.

In short, philosophers of the Design Turn need to (re)connect design ethics with normative ethical theories - and, for the present purpose, normative views of the good life — and to defend the design and technology with their favourite normative theory.

\footnotetext{
${ }^{14}$ See, e.g. Albrechtslund (2007) and Manders-Huits (2010). In her paper, Manders-Huits (2010) has also identified problems in VSD's methodology, particularly VSD's notion of 'stakeholders' and the relations between the conceptual, empirical and normative investigations within VSD. I will not answer them here, but will return to them below.
} 
I have identified two questions for philosophers of the Design Turn, and I have also tried to show that binding recommendation should be an integral part of the Design Turn. There are, of course, different ways to conceive binding recommendations; and, relatedly, there are different ways to offer them to the public. Here, building on Michael Walzer's notion of thick morality and his view of social criticism, I propose a Walzerian approach to the practice of (binding) recommendation. ${ }^{15}$ I think the Walzerian approach can provide a satisfactory answer to the aforementioned questions, and it can also mitigate the paternalistic worry from binding recommendation. In Walzer's view, social criticism should be

(i) Hermeneutical. It is about (re-)interpretation of the existing morality. It is, thus, essentially hermeneutical. It starts with the assumption that the existing views of the good life have some validity. And, from this, the approach aims to understand how they make sense to us.

(ii) A Form of Immanent Critique. It begins from within not from without, that is - it argues from the existing views of the good life, but not from some universal or objective theories. Its critical force, therefore, does not come externally. It criticises personal behaviours or social practices by going back to the views of the good life held by the person or the society. A Walzerian approach, therefore, is a form of immanent critique.

(iii) Participatory. It requires the researchers to engage with the public. It involves participation and engagement in the current debate by paying real attention to it and responding seriously.

(iv) Empirical. It is built on the existing views of the good life. Hence, it is, in an important sense, empirical. It is not abstract theorising, but to examine actual behaviours, social practices and/or public discourses in the society. It is, in other words, based on empirical data.

(v) Pluralistic. It recognises the fact that societies and cultures can be different. It is this recognition that drives the approach to start from actual behaviours, social practices or public discourses in the society in order to avoid imposing a false sense of universality or objectivity. As such, it starts with the assumption of a plurality of the views of the good life. While it does not preclude the possibility of universality or objectivity, it does insist that universality or objectivity should not be the assumption to begin with.

The Walzerian approach, I think, presents interesting answers to the two questions summarised in the previous section. First, to the question about the connection between design ethics and normative ethical theories, the Walzerian approach takes the users' values as a starting point, and it scrutinises and (re)interprets them using the resources within their culture. Accordingly, the resources to make normative judgement are already there, and they are being expressed in the public discourse. This is exactly why it is important, in the Walzerian approach proposed here, that philosophers ought to participate in the public discourse and

$\overline{15}$ See, Walzer (1981, 1984, 1987, 1988, 1989, 1994, 2007). 
engage with the public, who are themselves interpreters of values. It is by virtue of their participation and engagement, philosophers derive those values to be embedded (or omitted) in technology that are truly at the heart of the users. In short, the Walzerian approach searches for values in the public discourse, and to scrutinise and (re-)interpret them together with the users, i.e. the public. In this way, philosophers can become a proxy of the reflected public and supply valuable inputs to designers and engineers. ${ }^{16}$

More importantly, perhaps, is its answer to the second question. I have already argued that if the objective of the Design Turn is to promote (or demote) certain values that aim to enhance people's good life, then the gap between designer's intention and the actual contexts of use must be bridged. To do this, philosophers must be prepared to stand up for the values embedded (or omitted) in the technology. ${ }^{17}$ And, offering binding recommendations is one effective way to do so. And, I have also tried to show that philosophers should not be afraid of offering binding recommendations because of the paternalistic worry it raises. Still, the related worry about elitism appears to persist, namely on what (superior) ground are philosophers warranted to tell people how they ought to live their own life?

On this worry, there is an immediate response available to the Walzerian approach. In this approach, philosophers, working with designers and engineers, should only embed those values which the users themselves endear. Since the selected values are derived from philosophers' reflection and interpretation, and revised and buttressed through their participation and engagement with the public, the values - being values of the users - provide a legitimate ground for instructions and criticisms. Also, recall the worry about elitism arises from the superiority condition. Elitism from binding recommendation is deemed problematic because it is argued there is no expert of the good life, and thus telling people how they should live their own life with binding recommendations is an insult to them. But, the Walzerian approach does in fact allow philosophers to acquire a form of expertise on the good life. Since philosophers reflect on and (re-)interpret existing views of the good life with the public through participation and engagement, it should be relatively uncontroversial to claim that they are-or, can be-experts of the existing views of the good life. In this respect, the Walzerian approach provide a more solid ground for philosophers to defend the values they seek to embed through design. After all, those values are users' own values. At the same time, through the Walzerian approach's connectedness, philosophers can understand better and more immediately user's deviations from designer's intention and, in return, it enables

\footnotetext{
${ }^{16}$ It is, in fact, very similar to "empirical investigations" in VSD's tripartite methodology. But, the current approach differs from it in that (i) it insist that "empirical investigation" should be the starting point of the normative analysis and (ii) that researchers are not observers, who take a distance from the subjects, but they are participants, who are deeply involved and engaged in the discussion of the values.

17 Of course, not all deviations from the intended use are bad by definition. Sometimes, a deviation from the intended use can realise important values for the users. The Walzerian approach proposed here, in virtue of its participatory nature, will also take that into account. In this scenario, philosophers should scrutinise and (re)interpret the values realised by the deviation, and to help designers and engineers to incorporate them into future designs.
} 
philosophers to respond to them-especially to those positive deviations-more timely and appropriately.

\section{Conclusion}

I begin this paper by identifying two types of recommendation, i.e. binding and nonbinding recommendation. And, I suggest that binding recommendation is susceptible to the charge of paternalism, which is objectionable to many philosophers. I then presented an argument showing that paternalism engendered by technology is inevitable and is currently practised by designers, engineers and others in the chain of production. And, I attempt to urge philosophers and ethicists of technology to reconsider their role in light of its inevitability. In this respect, philosophers of the Design Turn are the group of researchers who accept the inevitability of paternalism engendered by technology and take up the opportunities and challenges it creates by being more proactive in the ethical and prudential dimensions of design and technology.

Still, there are two questions for philosophers of the Design Turn, namely (i) the methodological and normative question on the relationship between values and design of technology and (ii) the gap between designer's intention and the actual contexts of use. Particularly, I have pointed out that if the objective of the Design Turn is to be realised, philosophers must bridge the gap between designer's intention and the actual contexts of use. I have proposed a Walzerian approach in response to (i) and (ii). I pointed out that existing moralities offer abundant resources for philosophers to justify the selected values to designers and engineers as well as the public. This approach also enables philosophers to be in a right position to instruct the users and to criticise negative deviations from designer's intention. At the same time, it should enable philosophers to help designers and engineers to adopt positive deviations in future designs.

I want to end this paper by reminding what this paper is not about. First, this is not a paper about paternalism in the strict sense. Here, my aim is only to argue that if philosophers think that offering binding recommendations to the public is paternalistic and thereby objectionable, they should not do so. Since philosophers are in a better position-at least, according to the Walzerian approach I proposed here-to examine the good life, they should fare better than designers and engineers, who do not necessarily pay enough attention to ethical and prudential dimensions of design and technology, in response to the inevitability of paternalism. Second, this is also not a paper on design ethics. While I have discussed design ethics here, I only want to point out that design ethics, which is one of the best responses to the inevitability of paternalism, is insufficient without binding recommendation. In short, this paper is an attempt to reassert the importance of (binding) recommendation, which has largely disappeared from recent work in philosophy and ethics of technology. However, even if the view presented in this paper is theoretically justified, its practical feasibility remains to be proven. Particularly, whether (and how) philosophers will be heard by designers and engineers and the public has to be investigated further. I have not offered any 
solutions to the practical problems associated with the practice of recommendation; it is clear that philosophers, in order to collaborate with designers and engineers and to communicate with the public, need to develop different skill sets. But, if the view presented in this paper is correct, philosophers are needed for the good of the public, and it is our duty to reinvent ourselves to take up the opportunities and challenges.

Open Access This article is distributed under the terms of the Creative Commons Attribution Noncommercial License which permits any noncommercial use, distribution, and reproduction in any medium, provided the original author(s) and source are credited.

\section{References}

Alcoff, L. M. (2002). Does the public intellectual have intellectual integrity? Metaphilosophy, 33(5), 521-534.

Albrechtslund, A. (2007). Ethics and technology design. Ethics and Information Technology, 9, 63-72.

Brey, P. (2000). Disclosive computer ethics. Computers and Society, 30(4), 10-16.

Brey, P. (2010a). Philosophy of technology after the empirical turn. Techné: Research in Philosophy and Technology, 14(1), 36-48.

Brey, P. (2010b). Values in technology and disclosive computer ethics. In Luciano Floridi (Ed.), The Cambridge handbook of information and computer ethics (pp. 41-58). Cambridge: Cambridge University Press.

Carr, N. (2010). The shallows: What the internet is doing to our brains. New York: W.W. Norton.

Cowley, C. (2005). A New rejection of moral expertise. Medicine, Health Care and Philosophy, 8, 273-279.

Cummings, M. L. (2006). Integrating ethics in design through the value-sensitive design approach. Science and Engineering Ethics, 12, 701-715.

Dworkin, G. (2010). Paternalism. In Edward N. Z. (ed.), The Stanford encyclopedia of philosophy (Summer 2010 Edition): http://plato.stanford.edu/archives/sum2010/entries/paternalism/.

Feinberg, J. (1986). Harm to self. New York: Oxford University Press.

Friedman, B., \& Kahn, P. H. (2007). Human values, ethics, and design. In A. Sears \& J. A. Jacko (Eds.), The human-computer interaction handbook: Fundamentals, evolving technologies, and emerging applications (Second ed., pp. 1241-1266). Boca Raton, FL: CRC Press.

Friedman, B., Kahn, P. H., \& Borning, A. (2008). Value sensitive design and information systems. In K. E. Himma \& H. T. Tavani (Eds.), Handbook of Information and computer ethics (pp. 69-108). Hoboken, NJ: Wiley.

Fuller, S. (2004). Intellectuals: An endangered species in the twenty-first century? Economy and Society, 33(4), 463-483.

Garren, D. J. (2006). Paternalism, part I. Philosophical Books, 47(4), 334-341.

Garren, D. J. (2007). Paternalism, part II. Philosophical Books, 48(1), 50-59.

Grill, K. (2011). Paternalism. In Ruth Chadwick, R (ed.), Encyclopedia of applied ethics (Second Edition). San Diego: Academic Press. Available Online at: http://kallegrill.se/texts/Paternalism\% 20preprint.pdf.

Iversen, O. S., Halskov, K., \& Leong, T. W. (2010). In Proceedings of the 11th Biennial Participatory Design Conference (pp. 91-100), November, 2010, Sydney, Australia.

Jacoby, R. (2000). The last intellectuals: American culture in the age of Academe (2000th ed.). New York: Basic Books.

Jacoby, R. (2009). Last thoughts on the last intellectuals. Society, 46(1), 38-44.

Keen, A. (2007). The cult of the amateur: How today's internet is killing our culture. New York: Doubleday/Currency.

Lanier, J. (2010). You are not a gadget: A manifesto. New York: Alfred A. Knopf.

Manders-Huits, N. (2010). What values in design? The challenge of incorporating moral values into design. Science and Engineering Ethics. doi:10.1007/s11948-010-9198-2.

Muller, M. J. (2007). Participatory design: The third space in HCI. In A. Sears \& J. A. Jacko (Eds.), The Human-Computer Interaction Handbook: Fundamentals, Evolving Technologies, and Emerging Applications (Second ed., pp. 1061-1081). Boca Raton, FL: CRC Press. 
Muller, M. J., \& Kuhn, S. (1993). Participatory design. Communications of the ACM, 36(6), 24-28.

Powers, William. (2010). Hamlet's blackberry: A practical philosophy for building a good life in the digital age. New York: Harper.

Rawls, J. (1993). Political liberalism. New York: Columbia University Press.

Shirky, C. (2010). Cognitive surplus: Creativity and generosity in a connected age. London: Allen Lane.

Scoccia, D. (2008). In defence of hard paternalism. Law and Philosophy, 27, 351-381.

Steinkamp, N. L., Gordijn, B., \& ten Have, H. A. M. J. (2008). Debating ethical expertise. Kennedy Institute of Ethics Journal, 18(2), 173-192.

Thaler, R. H., \& Sunstein, C. (2008). Nudge: Improving decisions about health, wealth, and happiness. New Haven: Yale University Press.

Van De Veer, D. (1979). Paternalism and subsequent consent. Canadian Journal of Philosophy, 9(4), 631-642.

Van den Hoven, J. (2008). Moral methodology and information technology. In K. E. Himma \& H. T. Tavani (Eds.), Handbook of information and computer ethics (pp. 49-67). Hoboken, NJ: Wiley.

Verbeek, P. P. C. C. (2006). Materializing morality: Design ethics and technological mediation. Science Technology and Human Values, 31(3), 361-380.

Verbeek, P. P. C. C. (2008). Morality in design: Design ethics and the morality of technological artifacts. In P. Vermass, P. Kroes, A. Light, \& S. A. Moore (Eds.), Philosophy and design: From engineering to architecture (pp. 91-103). Dordrecht: Springer.

Verbeek, P. P. C. C. (2010). Accompanying technology. Techné: Research in Philosophy and Technology, 14(1), 49-54.

Walzer, M. (1981). Philosophy and democracy. Political Theory, 9, 379-399. Reprinted in Michael Walzer (2007).

Walzer, M. (1984). Liberalism and the art of separation. Political Theory, 12, 315-330. Reprinted in Michael Walzer (2007).

Walzer, M. (1987). Interpretation and social criticism. Cambridge, Mass: Harvard University Press.

Walzer, M. (1988). The company of critics: Social criticism and political commitment in the twentieth century. New York: Basic Books.

Walzer, M. (1989). A critique of philosophical conversation. Philosophical Forum, 21, 182-196. Reprinted in Michael Walzer (2007).

Walzer, M. (1994). Thick and thin: Moral argument at home and abroad. Notre Dame: University of Notre Dame Press.

Walzer, Michael. (2007). Thinking politically: Essays in political theory. New Haven: Yale University Press.

Winner, L. (1986). Do artifacts have politics? In the whale and the reactor: A search for limits in an age of high technology (pp. 19-39). Chicago: University of Chicago Press. 